\title{
Timing of Morphine Administration Differentially Alters Paraventricular Thalamic Neuron Activity
}

\author{
Dillon S. McDevitt ${ }^{1,2}$ and Nicholas M. Graziane ${ }^{1}$ \\ https://doi.org/10.1523/ENEURO.0377-19.2019 \\ ${ }^{1}$ Departments of Anesthesiology and Perioperative Medicine and Pharmacology, Penn State College of Medicine, \\ Hershey, PA 17033 and ${ }^{2}$ Neuroscience Graduate Program, Penn State College of Medicine, Hershey, PA 17033
}

\begin{abstract}
The paraventricular thalamic nucleus (PVT) is a brain region involved in regulating arousal, goal-oriented behaviors, and drug seeking, all key factors playing a role in substance use disorder. Given this, we investigated the temporal effects of administering morphine, an opioid with strongly addictive properties, on PVT neuronal function in mice using acute brain slices. Here, we show that morphine administration and electrophysiological recordings that occur during periods of animal inactivity (light cycle) elicit increases in PVT neuronal function during a 24-h abstinence time point. Furthermore, we show that morphine-induced increases in PVT neuronal activity at 24-h abstinence are occluded when morphine administration and recordings are performed during an animals' active state (dark cycle). Based on our electrophysiological results combined with previous findings demonstrating that PVT neuronal activity regulates drug-seeking behaviors, we investigated whether timing morphine administration with periods of vigilance (dark cycle) would decrease drug-seeking behaviors in an animal model of substance use disorder. We found that context-induced morphine-seeking behaviors were intact regardless of the time morphine was administered (e.g., light cycle or dark cycle). Our electrophysiological results suggest that timing morphine with various states of arousal may impact the firing of PVT neurons during abstinence. Although, this may not impact context-induced drug-seeking behaviors.
\end{abstract}

Key words: brain slice electrophysiology; circadian cycle; conditioned place preference; light/dark cycle; morphine; paraventricular thalamic nucleus

\section{Significance Statement}

Here, we show that the timing of morphine administration differentially alters paraventricular thalamic nucleus (PVT) neuronal function. Timing morphine administration during an animals' inactive state increases PVT neuronal activity, while this morphine-induced effect is occluded when morphine administration occurs during an animals' active state. Given evidence that PVT neuronal activity regulates drug-seeking behaviors, we investigated whether timing morphine administration with periods of vigilance would decrease drugseeking behaviors in an animal model of substance use disorder. We found that morphine-induced conditioned place preference (CPP) was intact regardless of the time morphine was administered. Our results suggest that timing morphine with various states of arousal impacts the firing of PVT neurons during abstinence, but not morphine-induced CPP.

\section{Introduction}

Opioids induce sleep-wake disturbances in humans and in rodents (Oyefeso et al., 1997; Stinus et al., 1998; Li

Received September 19, 2019; accepted November 26, 2019; First published December 4, 2019

The authors declare no competing financial interests. et al., 2009), with evidence suggesting that sleep disturbances facilitate drug-seeking behaviors (Hasler et al., 2012; Logan et al., 2018). There has been substantial

Author contributions: D.S.M. and N.M.G. designed research; D.S.M. and N.M.G. performed research; D.S.M. and N.M.G. analyzed data; D.S.M. and N.M.G. wrote the paper. 
work dedicated to understanding the mechanisms mediating opioid-induced sleep disturbances, with a focus on opioid-induced changes in genes and proteins whose expression is driven by circadian cycles [e.g., circadian locomotor output cycles kaput (CLOCK) or period (Per1, Per2 and Per3); Hasler et al., 2012; Logan et al., 2014]. However, brain regions that link opioid-induced sleep disturbances with drug-seeking behaviors remains largely unknown.

The paraventricular nucleus of the thalamus (PVT) is a midline thalamic nucleus that receives dense innervation from brain regions, including the locus coeruleus, dorsal raphe, penduculopontine tegmental nucleus, orexin neurons in the hypothalamus, and suprachiasmatic nucleus, that are involved in regulating wakefulness (the presence of voluntary motor activation and responsiveness to internal and external stimuli), and rapid eye movement (REM), and non-REM (NREM) sleep patterns (Novak et al., 2000; Peng and Bentivoglio, 2004; Li and Kirouac, 2012; Kirouac, 2015; Scammell et al., 2017). Additionally, the PVT projects to several regions of the greater reward circuit, including the nucleus accumbens, amygdala, and medial prefrontal cortex (Li and Kirouac, 2008; Kirouac, 2015; Dong et al., 2017). Functionally, the PVT regulates wakefulness (Herrera et al., 2016; Mátyás et al., 2018; Ren et al., 2018), with arousal/awake states coinciding with increases in PVT neuronal activity (Kolaj et al., 2012). In parallel, cocaine, a drug of abuse that disrupts sleep cycles (Schierenbeck et al., 2008) and promotes drugseeking (Liu et al., 2016), increases PVT neuronal excitability (Yeoh et al., 2014), while reducing PVT activity suppresses cocaine or alcohol-seeking behaviors (Hamlin et al., 2009; James et al., 2010; Browning et al., 2014; Neumann et al., 2016). Given this, we investigated the effects of morphine, an opioid with high risk of addiction and known to induce sleep disturbances (Kay, 1975; Shaw et al., 2005; Dimsdale et al., 2007; Robertson et al., 2016), on PVT neuronal function. To test this, we used whole-cell patch clamp electrophysiology in mouse brain slices to investigate morphine-induced intrinsic and synaptic effects on PVT neurons $24 \mathrm{~h}$ following repeated morphine administration. Additionally, we investigated whether morphine-induced alterations on PVT neuronal function may be differentially affected by the timing of morphine administration, which we tested by administer-

This work was supported by the Brain \& Behavior National Alliance for Research on Schizophrenia \& Depression Young Investigator Award 27364NG, the Pennsylvania State Junior Faculty Scholar Award (N.M.G.), the Pennsylvania Department of Health using Tobacco CURE Funds (N.M.G.), and the Pennsylvania State Research Allocation Project Grant (N.M.G.).

Acknowledgements: We thank Dr. Diane McCloskey for edits and formatting and the Silberman lab for their comments and suggestions on the project. Morphine was provided by the Drug Supply Program of National Institute on Drug Abuse National Institutes of Health.

Correspondence should be addressed to Nicholas M. Graziane at ngraziane@pennstatehealth.psu.edu.

https://doi.org/10.1523/ENEURO.0377-19.2019

Copyright (C) 2019 McDevitt and Graziane

This is an open-access article distributed under the terms of the Creative Commons Attribution 4.0 International license, which permits unrestricted use, distribution and reproduction in any medium provided that the original work is properly attributed. ing morphine during animals' inactive (light cycle) or active states (dark cycle) when PVT neuronal function is decreased or increased, respectively. Finally, given the evidence that the PVT is influenced by circadian rhythms (Peng et al., 1995; Novak and Nunez, 1998; Kolaj et al., 2012), we investigated whether timing morphine administration with PVT activity states impacted morphineinduced conditioned place preference (CPP), a model of addiction-like behavior (Bardo and Bevins, 2000) that is influenced by the circadian cycle (Abarca et al., 2002; Kurtuncu et al., 2004).

\section{Materials and Methods}

\section{Animals}

All experiments were done in accordance with procedures approved by the Pennsylvania State University College of Medicine Institutional Animal Care and Use Committee Institutional Animal Care and Use Committee. Male and female C57BL/6 mice aged 5-10 weeks were purchased from The Jackson Laboratory (stock \#000664), singly housed, and maintained on a regular $12 / 12 \mathrm{~h}$ light/ dark cycle (lights on 7 A.M., lights off 7 P.M.) with ad libitum food and water. For dark cycle electrophysiological experiments (Figs. 1, 3, and 4), mice were switched to a lights on 7 P.M., lights off 7 A.M. schedule and allowed to adapt to the new cycle for two weeks before receiving injections. We found that two weeks of acclimation is sufficient to promote diurnal variations in PVT neuronal firing patterns in mice (Fig. 1) as previously observed in rats (Kolaj et al., 2012). For dark cycle CPP experiments, animals were housed on a regular 12-h light/dark cycle. Since no significant differences were observed between sexes in our electrophysiological experiments (Table 1), all behavioral tests were run with male C57BL/6 mice aged 5-10 weeks (The Jackson Laboratory, stock \#000664) who were singly housed.

\section{Drugs}

(-)-Morphine sulfate pentahydrate was provided by the National Institute on Drug Abuse Drug Supply Program. NBQX and AP5 were purchased from Tocris Biosciences.

\section{Repeated systemic injections of saline or morphine}

Before drug administration, mice were allowed to acclimate to their home cages for $>5 \mathrm{~d}$. For drug treatment, we used a 5-d repeated drug administration procedure (Graziane et al., 2016). In all electrophysiological experiments (Figs. 1-Figs. 4), once per day for $5 \mathrm{~d}$, mice were taken out of the home cages at Zeitgeber time (ZT)2 (for experiments performed during the light cycle) or ZT14 (for experiments performed during the dark cycle; ZTO = lights on, ZT12 = lights off) for an intraperitoneal injection of either (-)-morphine sulfate pentahydrate $(10 \mathrm{mg} / \mathrm{kg}$ in saline) or the same volume of saline, and then placed back to the home cage. Animals were randomly selected for each drug treatment. Morphine-treated or salinetreated animals were then used for electrophysiological recordings $\sim 24 \mathrm{~h}$ following the last injection. As previously published (Robinson and Kolb, 1999), this drugtreatment paradigm does not produce noticeable signs of 
A1

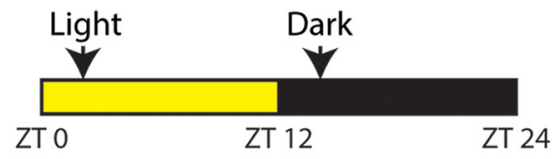

A2

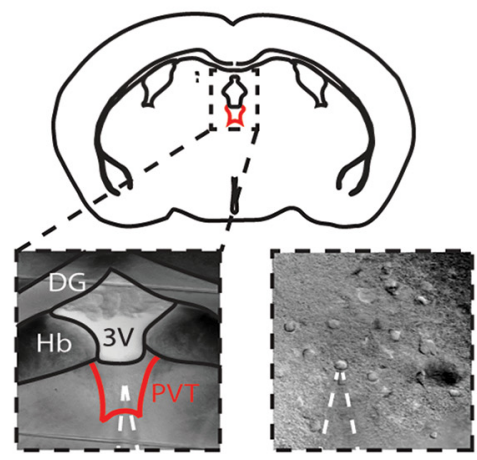

C

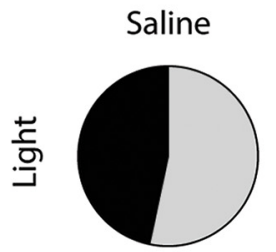

$=53.33 \%$ Silent

- $46.67 \%$ Spont. Firing

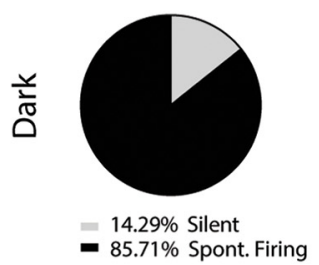

B

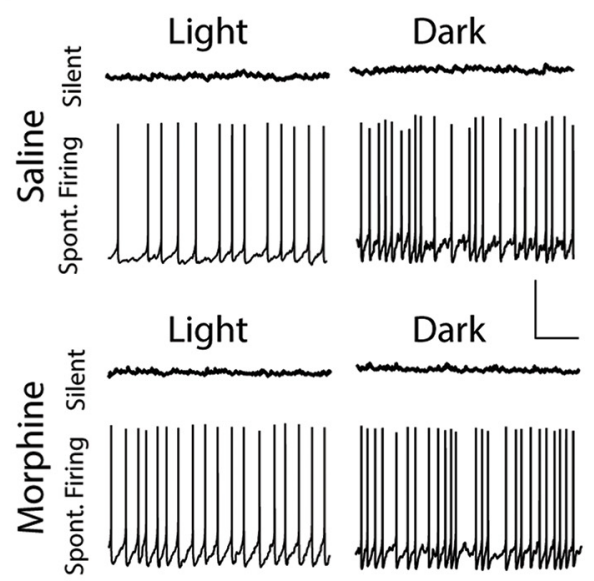

D

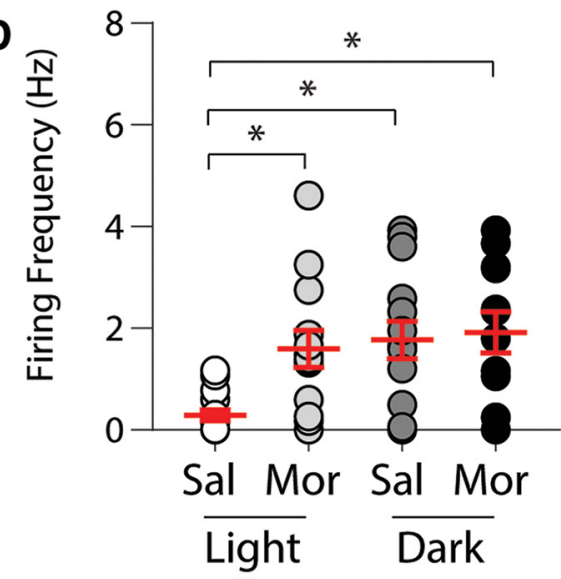

Figure 1. Morphine administration during the light cycle increases the number of spontaneously firing PVT neurons. A1, ZT timeline showing times in which acute brain slices were prepared. Slices were prepared at either ZT2 (light) or ZT14 (dark). A2, Coronal mouse brain slice showing an electrophysiological recording in the PVT (dashed shape outlines the recording electrode that is patched onto a PVT neuron). $\boldsymbol{B}$, Representative traces showing the firing of PVT neurons $24 \mathrm{~h}$ following saline or morphine administration during light or dark cycles. C, Quantification of silent or spontaneously firing PVT neurons following repeated saline or morphine treatment. $\boldsymbol{D}$, Summary showing the overall firing frequency of PVT neurons $24 \mathrm{~h}$ following repeated saline (Sal) or morphine (Mor) administration $\left(F_{(3,52)}=5.52, p=0.002\right.$, one-way ANOVA); $* p<0.05$. Scale bars: $40 \mathrm{mV}, 2 \mathrm{~s}$.

withdrawal and was chosen because it induces locomotor sensitization and CPP (Spanagel et al., 1998; Mueller et al., 2002; Graziane et al., 2016).

\section{Acute brain slice preparation}

Mice were deeply anesthetized with isoflurane and cardiac perfused with an ice-cold NMDG-based cutting solution containing the following: $135 \mathrm{mM} \mathrm{N}$-methyl-D- glucamine, $1 \mathrm{mM} \mathrm{KCl}, 1.2 \mathrm{mM} \mathrm{KH}_{2} \mathrm{PO}_{4}, 0.5 \mathrm{mM} \mathrm{CaCl}_{2}$, $1.5 \mathrm{mM} \mathrm{MgCl} 2,20 \mathrm{mM}$ choline- $\mathrm{HCO}_{3}$, and $11 \mathrm{mM}$ glucose, saturated with $95 \% \mathrm{O}_{2} / 5 \% \mathrm{CO}_{2}$, adjusted to $\mathrm{pH} 7.4$ with $\mathrm{HCl}$, osmolality adjusted to 305 . Following perfusion, mice were decapitated and brains were rapidly removed; 250- $\mu \mathrm{m}$ coronal brain slices containing the PVT were prepared, via a Leica VT1200s vibratome, in $4^{\circ} \mathrm{C}$ NMDG cutting solution, and the lateral hemispheres $(\sim 2.5 \mathrm{~mm}$

Table 1. Sex comparisons within electrophysiological assessments

\begin{tabular}{|c|c|c|c|c|c|c|}
\hline \multirow[b]{2}{*}{ Experiment } & \multicolumn{2}{|c|}{ Saline } & \multicolumn{4}{|c|}{ Morphine } \\
\hline & Male & Female & $p$ value & Male & Female & $p$ value \\
\hline Spontaneously firing light (Fig. 1) & $0.34 \pm 0.22(5)$ & $0.27 \pm 0.13(10)$ & 0.91 & $1.41 \pm 1.07(4)$ & $1.67 \pm 0.31(9)$ & 0.75 \\
\hline Spontaneously firing dark (Fig. 1) & $1.77 \pm 0.24(4)$ & $1.62 \pm 0.51(10)$ & 0.85 & $2.22 \pm 0.59(3)$ & $1.83 \pm 0.50(11)$ & 0.71 \\
\hline IME light 100 pA (Fig. 2) & $7.88 \pm 1.67(8)$ & $9.92 \pm 2.11(13)$ & 0.50 & $16.87 \pm 1.86(15)$ & $11.00 \pm 4.71(4)$ & 0.19 \\
\hline IME dark 100 pA (Fig. 3) & $25.2 \pm 4.76(5)$ & $20.35 \pm 1.33(14)$ & 0.19 & $17.28 \pm 2.59(7)$ & $21.00 \pm 0.82(14)$ & 0.10 \\
\hline AMPA/NMDA ratios light (Fig. 4) & $0.77 \pm 0.05(4)$ & $0.85 \pm 0.11(5)$ & 0.55 & $1.46 \pm 0.41(3)$ & $1.27 \pm 0.12(5)$ & 0.59 \\
\hline AMPA/NMDA ratios dark (Fig. 4) & $1.43 \pm 0.23(5)$ & $1.05 \pm 0.08(6)$ & 0.14 & $1.01 \pm 0.26(3)$ & $1.19 \pm 0.14(8)$ & 0.75 \\
\hline
\end{tabular}

Mean \pm SEM; number of cells $(n)$; Student's $t$-test was used for statistical measures. 
lateral from the midline) were removed to allow for the slices to fit into the recording chamber. Before recording, slices were allowed to recover in artificial cerebral spinal fluid (aCSF) containing the following: $119 \mathrm{mM} \mathrm{NaCl}, 2.5$ $\mathrm{mM} \mathrm{KCl}, 2.5 \mathrm{mM} \mathrm{CaCl}_{2}, 1.3 \mathrm{mM} \mathrm{MgCl}_{2}, 1 \mathrm{mM} \mathrm{NaH}_{2} \mathrm{PO}_{4}$, $26.2 \mathrm{mM} \mathrm{NaHCO}_{3}$, and $11 \mathrm{mM}$ glucose, osmolality of 290, at $31^{\circ} \mathrm{C}$ for $30 \mathrm{~min}$ followed by $30 \mathrm{~min}$ at $20-22^{\circ} \mathrm{C}$. After a $1-\mathrm{h}$ recovery period, slices were kept at $20-22^{\circ} \mathrm{C}$ for the rest of the recording day.

\section{Electrophysiology}

Whole-cell recording. All recordings were made from the PVT of mice spanning between bregma -0.94 and $-2.18 \mathrm{~mm}$ (Paxinos and Franklin, 2004). Therefore, we randomly sampled neurons located in the middle PVT (Paxinos and Franklin, 2004) corresponding to a region that projects to the reward neurocircuit ( $\mathrm{Li}$ and Kirouac, 2008; Zhu et al., 2016; Li et al., 2018) and is implicated in wakefulness (Ren et al., 2018). These coordinates exclude what are considered the anterior and posterior PVT (Paxinos and Franklin, 2004). Recordings within bregma -0.94 and $-2.18 \mathrm{~mm}$ were evenly sampled with no bias between experimental groups. Slices were transferred to a recording chamber and neurons were visualized using infrared differential interference contrast microscopy. During recording, slices were superfused with aCSF at room temperature. For recordings of spontaneously firing neurons (Fig. 1), recording electrodes [2-5 $\mathrm{M} \Omega$; borosilicate glass capillaries (WPI \#1B150F-4) pulled on a horizontal puller from Sutter Instruments (model P-97)] were filled with a potassium-based internal solution containing the following: $130 \mathrm{mM} \mathrm{KMeSO}$, $10 \mathrm{mM} \mathrm{KCl,} 10 \mathrm{mM}$ HEPES, 0.4 mM EGTA, $2 \mathrm{mM} \mathrm{MgCl}-6 \mathrm{H}_{2} 0,3 \mathrm{mM} \mathrm{Mg-ATP}$, and 0.5 $\mathrm{mM}$ Na-GTP, $\mathrm{pH}$ 7.2-7.4. Immediately following wholecell configuration, spontaneous activity was analyzed over a 100 s duration. As previously shown, cell dialysis of the internal solution in whole-cell patch-clamp configuration does not impact the spontaneous activity of PVT neurons (Kolaj et al., 2012). For intrinsic membrane excitability experiments, recording electrodes (2-5 M $\Omega$ ) were filled with a potassium-based internal solution (see above in the Electrophysiology subsection of the Materials and Methods). Resting membrane potential was recorded immediately following break-in. Before beginning the protocol, cells were adjusted to a resting membrane voltage of $-60 \mathrm{mV}$. This typically was achieved with $<30 \mathrm{pA}$ current injection, and cells were discarded if the current needed to adjust the cell to $-60 \mathrm{mV}$ was $>50 \mathrm{pA}$. A current step protocol, consisting of $600 \mathrm{~ms}$ steps ranging from -100 to $+100 \mathrm{pA}$ in $20 \mathrm{pA}$ increments, was conducted with a $20 \mathrm{~s}$ intrasweep interval. The number of action potentials observed at each current step was recorded. $\mathrm{I}_{\mathrm{H}}$ currents were calculated by measuring the amplitude of the peak current minus the steady-state current at a -60 pA hyperpolarizing step. Cells were classified into a firing phenotype based off of their firing behavior at the +100 pA step. We observed four major phenotypes: tonic firing, initial burst firing, delayed burst firing, and initial single spike. For AMPA receptor (AMPAR)/NMDA receptor (NMDAR) ratio experiments, recording electrodes (2-5 $M \Omega$ ) were filled with a cesium-based internal solution the following: $135 \mathrm{mM} \mathrm{CsMeSO}_{3}, 5 \mathrm{mM} \mathrm{CsCl}, 5 \mathrm{mM}$ TEA-Cl, $0.4 \mathrm{mM}$ EGTA (Cs), 20 mM HEPES, 2.5 mM Mg-ATP, 0.25 mM Na-GTP, and $1 \mathrm{mM} Q X-314(\mathrm{Br}), \mathrm{pH}$ 7.2-7.4. To isolate excitatory currents, picrotoxin $(100 \mu \mathrm{M})$ was included in the aCSF. To evoke postsynaptic currents, presynaptic afferents were stimulated via a constant-current stimulator (Digitimer) using a monopolar stimulating electrode (glass pipette filled with aCSF) positioned $100 \mu \mathrm{m}$ away from and along the same $z$-axis as the recorded neuron. Cells were held at $+40 \mathrm{mV}$ for the duration of the experiment. Once a stable baseline was observed, 50 traces were recorded. Following this, NBQX $(2 \mu \mathrm{M})$ was bath applied to isolate NMDAR-mediated currents. The drug was allowed to wash on, and 50 more sweeps were recorded. The AMPAR-mediated current was then obtained via digital subtraction of the NMDAR-mediated current from the mixed current. The AMPAR/NMDAR ratio was then calculated by taking the peak amplitude of the AMPAR-mediated current divided by the peak amplitude of the NMDAR-mediated current. Currents were recorded with either an Axon Multiclamp 700B amplifier or Sutter Double IPA, filtered at 2-3 kHz, and digitized at $20 \mathrm{kHz}$. For all recordings, series resistance was typically 10-25 $\mathrm{M} \Omega$, left uncompensated, and monitored throughout. Cells with a series resistance variation $>20 \%$ were discarded from analysis.

\section{CPP}

CPP chambers (Med Associates), located in the mouse housing room, consisted of three distinct compartments separated by manual guillotine-style doors. Each compartment had distinct contextual characteristics: the middle (neutral) compartment $\left(2.85^{\prime \prime} \times 5^{\prime \prime} \times 5^{\prime \prime}\right)$ had gray walls and gray plastic floor, while the choice compartments $\left(6.6^{\prime \prime} \times 5^{\prime \prime} \times 5^{\prime \prime}\right.$ each) had either white walls and stainlesssteel mesh floor or black walls and stainless-steel grid floor. All compartments were illuminated with a dim light during use. Immediately following use the entire preference chamber was cleaned thoroughly with a scent-free soap solution. Mouse locations, activity counts, and time spent in each compartment were collected via automated data-collection software (Med Associates) via infrared photobeam strips lining each compartment.

\section{Habituation}

During light or dark cycles, mice were placed in the center compartment with free access to all three compartments for 20 min once a day for $2 \mathrm{~d}$. Time spent (seconds) in each compartment was recorded.

\section{Conditioning}

Twenty-four hours after habituation, mice received $5 \mathrm{~d}$ of conditioning training. Morphine-paired compartments were assigned based on the least preferred side (a biased approach; Tzschentke, 2007), calculated by averaging time spent in each compartment over the two habituation days. Similar to conditioning studies with alcohol (Gremel et al., 2006), we find that C57BL/6 mice will reliably develop morphine CPP using a biased approach. During conditioning, mice received an injection of saline and were placed into the most preferred compartment for 40 
Table 2. Intrinsic properties of PVT neurons following saline or morphine treatment during the light or dark cycle

\begin{tabular}{|c|c|c|c|c|}
\hline & Saline light & Morphine light & Saline dark & Morphine dark \\
\hline $\mathrm{RMP}(\mathrm{mV})$ & $-59.36 \pm 0.90(33)$ & $-54.89 \pm 0.95(32) * *$ & $-51.38 \pm 1.04(33) * * \wedge$ & $-50.77 \pm 0.64(36) * * \wedge \wedge$ \\
\hline Capacitance (pF) & $56.57 \pm 3.61(23)$ & $56.79 \pm 3.48(19)$ & $64.27 \pm 4.49(22)$ & $62.58 \pm 4.25(24)$ \\
\hline Membrane resistance $(\mathrm{M} \Omega)$ & $562.4 \pm 54.2(23)$ & $563.0 \pm 75.79(19)$ & $1149 \pm 129(22) * * \wedge \wedge$ & $1193 \pm 166.2(24) * * \wedge \wedge$ \\
\hline Voltage sag (mV) & $4.09 \pm 0.40(15)$ & $4.85 \pm 1.08(15)$ & $6.69 \pm 1.17(16) *$ & $6.23 \pm 1.82(19)$ \\
\hline
\end{tabular}

Passive properties were compared across treatment groups using independent samples $t$ tests. Mean \pm SEM; number of cells $(n)$; $*$ significantly different from saline light; $\wedge$ signifcantly different from morphine light; $*$ or $\wedge p<0.05$, $* *$ or $\wedge \wedge p<0.01$. RMP, resting membrane potential.

min; $6 \mathrm{~h}$ later, mice received an injection of saline (control group) or morphine (10 mg/kg, i.p.) and were placed into their least preferred compartment for $40 \mathrm{~min}$ (Koo et al., 2014).

\section{Postconditioning}

Twenty-four hours after the last conditioning day, mice were placed in the center compartment, where they were allowed to move freely for $20 \mathrm{~min}$. Our postconditioning took place at a time point corresponding to $3 \mathrm{~h}$ before drug conditioning (e.g., morphine conditioning took place at ZT8, postconditioning took place the next day at ZT5). CPP scores were calculated as time spent in the drugpaired side minus the time spent on the same side during the preconditioning day (Bohn et al., 2003). Activity counts are defined as any beam break within a current zone. This is inclusive of grooming, rearing, and lateral movements.

\section{Statistical analysis}

All results are shown as mean \pm SEM. Each experiment was replicated in at least three animals. No data points were excluded. Sample size was presented as $n / m$, where " $n$ " refers to the number of cells and " $m$ " refers to the number of animals. Statistical significance was assessed in GraphPad Prism software using $\chi^{2}$ analysis, a one-way or two-way ANOVA with Bonferroni's correction for multiple comparisons as specified. F values for two-way ANOVA statistical comparisons represent interactions between variables unless otherwise stated. Our goal, a priori, was to examine pairwise comparisons between drug treatment and time of drug treatment regardless if the interaction effect between drug treatment and cell type was strong. Thus, before analysis, we created all possible independent groups based on drug treatment and cell type combinations and performed a one-way ANOVA with pairwise comparisons. The results from these pairwise comparisons from this one-way ANOVA would be equivalent to performing a two-way ANOVA with an interaction term (drug treatment, cell type, drug treatment $\times$ cell type interaction) and then performing post hoc pairwise comparisons on the interaction term from the two-way ANOVA model. Two-tail tests were performed for all studies.

\section{Results}

\section{Morphine increases basal PVT neuronal firing}

Evidence suggests that PVT neurons in nocturnal rats display diurnal variations in basal firing patterns such that increases in PVT neuronal activity are associated with increases in activity/arousal states (Kolaj et al., 2012). Similarly, in nocturnal mice expressing increases in activity/ arousal during the dark cycle (Schwartz and Zimmerman, 1990), we observed a greater number of spontaneously firing PVT neurons when electrophysiological recordings took place during saline-treated animals' dark cycle $\left(\chi^{2}(1)=\right.$ $4.89, p=0.03, \chi^{2}$ analysis; Figs. $1 B-D$ ).

We next tested the effects that repeated morphine (10 $\mathrm{mg} / \mathrm{kg}$, i.p.) exposure had on PVT neuron spontaneous firing and found that $24 \mathrm{~h}$ following a $5 \mathrm{~d}$, once daily repeated morphine injection paradigm during the light cycle, there was an increase in the number of spontaneously firing PVT neurons compared to saline-treated control mice $\left(\chi^{2}(1)=6.65, p=0.01, \chi^{2}\right.$ analysis; Fig. $\left.1 C\right)$, likely stemming from the depolarized resting membrane potential in PVT neurons from morphine-treated mice (Table 2; Kolaj et al., 2012). In contrast, the morphineinduced increase in spontaneously firing PVT neurons was likely occluded during dark cycle administration as saline-treated control animals showed increases in spontaneous neuronal firing $\left(\chi^{2}(1)=0.244, p=0.62, \chi^{2}\right.$ analysis; Fig. 1C). Furthermore, a one-way ANOVA post hoc analysis revealed that the overall firing frequency was significantly increased in morphine-treated animals during the light cycle (Bonferroni post hoc test, $p=0.041$ ), while during the dark cycle, this morphine-induced increase was likely occluded (Bonferroni post hoc test, light saline vs dark saline: $p=0.012$; dark saline versus dark morphine: $p>0.999$; Fig. $1 D$ ).

\section{Increased PVT intrinsic neuronal excitability following morphine is dependent on the timing of morphine administration}

In the PVT, changes in basal firing frequency are associated with changes in intrinsic membrane excitability (Kolaj et al., 2012), which sets the action potential threshold and determines, in part, the firing frequency (Daoudal and Debanne, 2003; Huang et al., 2011). We investigated the effects that repeated morphine administration has on the intrinsic membrane excitability of PVT neurons and tested whether these potential changes are influenced by the animals' activity states. Using whole-cell electrophysiological recordings, we measured the number of action potentials in response to depolarizing currents, as this approach is often used to measure intrinsic membrane excitability (Desai et al., 1999; Nelson et al., 2003; Zhang and Linden, 2003; Ishikawa et al., 2009; Wang et al., 2018). In mice receiving saline injections during the light cycle, we observed four firing phenotypes $24 \mathrm{~h}$ following the last saline injection; initial burst, single spike, delayed firing, and tonic firing (Fig. 2A). The distribution of recorded neurons after saline treatment $(n=21$ cells, five animals) was $38.10 \%$ tonic, $23.81 \%$ initial burst, $23.81 \%$ 

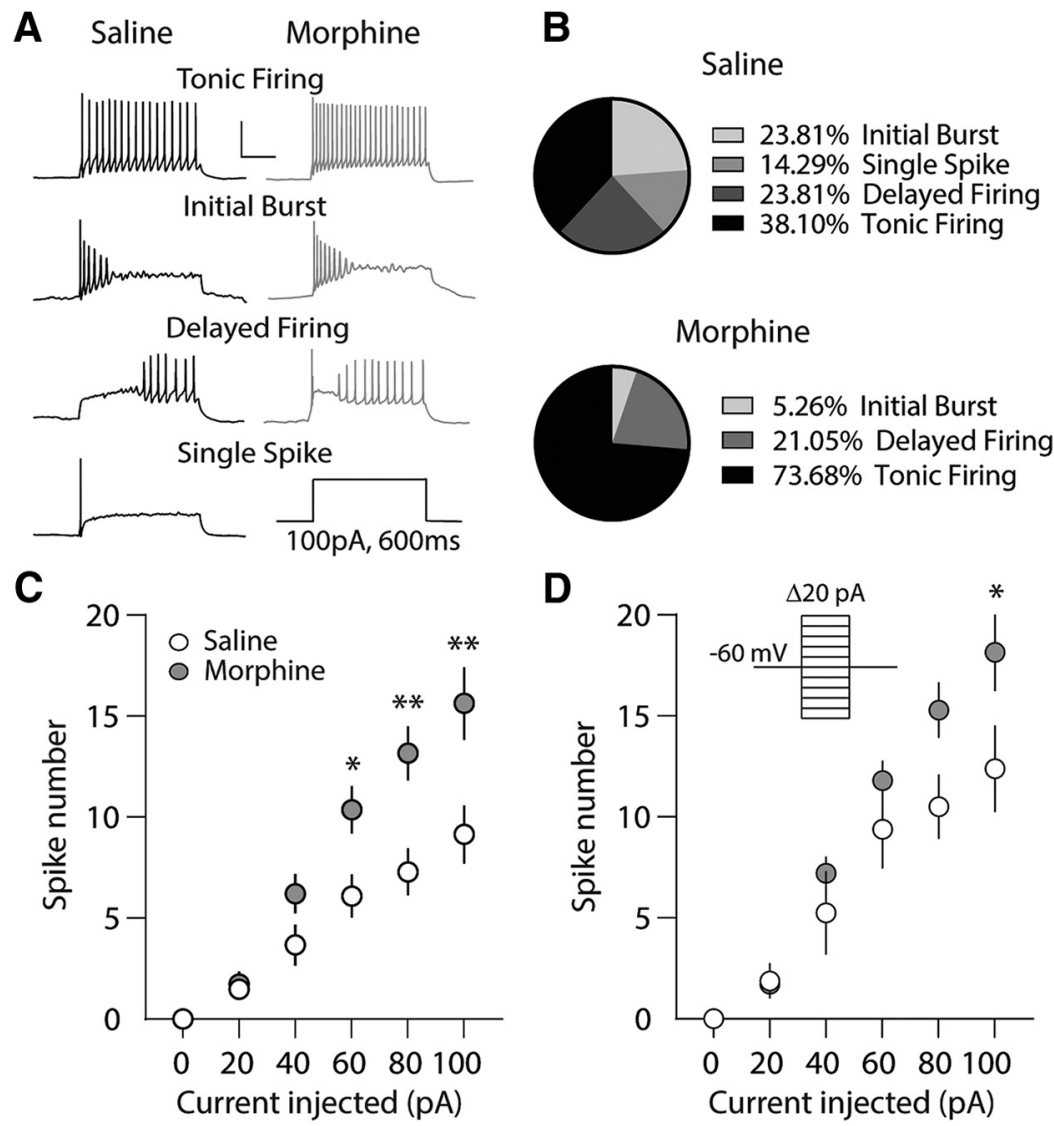

Figure 2. Repeated morphine exposure during the light cycle increases intrinsic membrane excitability of PVT neurons recorded in the light cycle. $\boldsymbol{A}$, Example traces demonstrating the four firing phenotypes observed in response to a depolarizing current injection (100 pA for $600 \mathrm{~ms}$ ); tonic firing, initial burst, delayed firing, and single spike (saline, left; morphine, right). Single spike firing patterns were not observed in neurons from animals treated with repeated morphine. Scale bars: $40 \mathrm{mV}, 200 \mathrm{~ms}$. B, Quantification of firing phenotypes in PVT neurons following repeated saline or morphine treatment. $\boldsymbol{C}$, Summary showing that $24 \mathrm{~h}$ following repeated morphine injections, the number of action potentials fired in PVT neurons is significantly increased at current injections of 60, 80, and 100 pA (saline: $n=21 / 5$; morphine: $19 / 6 ; F_{(5,190)}=5.14, p=0.0002$; two-way repeated measures ANOVA with Bonferroni post hoc test). $\boldsymbol{D}$, Summary showing that the number of action potentials fired from PVT neurons expressing tonic firing patterns $24 \mathrm{~h}$ after the last saline or morphine injection was significantly different at 100-pA current injection (saline: $n=8 / 3$; morphine: 14/4; $F_{(5,100)}=2.41$, $p=0.042$; two-way repeated measures ANOVA with Bonferroni post hoc test); $* p<0.05, * * p<0.01$.

delayed, and $14.29 \%$ single-spike (Fig. 2B). Twenty-four hours following morphine administration during the light cycle, the intrinsic membrane excitability of PVT neurons ( $n=19$, six animals) displayed only three firing phenotypes (tonic, initial burst, and delayed firing), lacking only single spikes (distribution: $73.68 \%$ tonic, $5.26 \%$ initial burst, and $21.05 \%$ delayed firing neurons; Fig. 2B). A $\chi^{2}$ analysis revealed no significant interaction between morphine exposure (i.e., saline vs morphine treatment) and firing type during the light cycle $\left(\chi^{2}(3)=7.33, p=0.06\right)$. However, we found that PVT neurons from morphinetreated animals had a significant increase in membrane excitability compared to saline controls during light cycle administration at current injections of 60,80 , and $100 \mathrm{pA}$ (Bonferroni post hoc test, $60 \mathrm{pA}: p=0.029$; $80 \mathrm{pA}: p=$ $0.0007 ; 100$ pA: $p=0.0001$; Fig. $2 C$ ). To test whether the observed morphine-induced increase in PVT neuronal membrane excitability was due to increases in the proportion of tonically firing neurons or a selective increase in action potential frequency of tonically firing neurons, we repeated our analysis by focusing on only neurons that tonically fired (Fig. 2D). In doing so, we found that morphine significantly increased the number of action potentials at the maximum current injected (Bonferroni post hoc test, $100 \mathrm{pA}: p=0.020)$. These results suggest that the observed significant increases in intrinsic membrane excitability at submaximal current injections (i.e., $60-80 \mathrm{pA}$ ) were attributed to a shift in the proportion of neurons exhibiting greater evoked firing frequencies, while at higher current injections (i.e., $100 \mathrm{pA}$ ), this shift was attributed to increases in the proportion of neurons exhibiting greater evoked firing frequencies and/or due to increases in action potential spike number in tonically firing neurons.

We next investigated whether morphine-induced increases in PVT neuronal intrinsic membrane excitability were maintained following morphine injections and subsequent recordings during the animals' active state (i.e., dark cycle). Our results show that PVT neurons ( $n=19$ cells, 5 animals) recorded from animals treated with saline 
A Saline Morphine

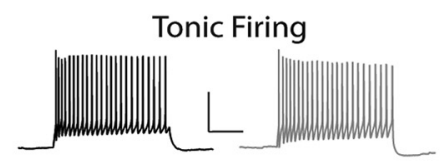

Delayed Firing Initial Burst
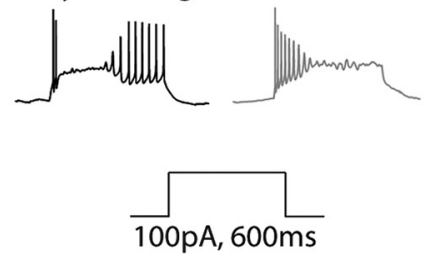

C

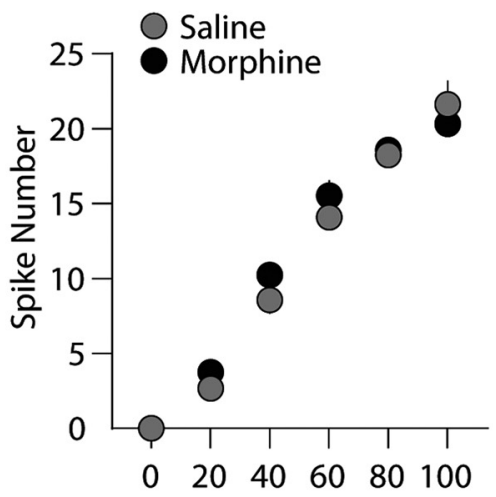

Injected Current (pA)
B

Saline
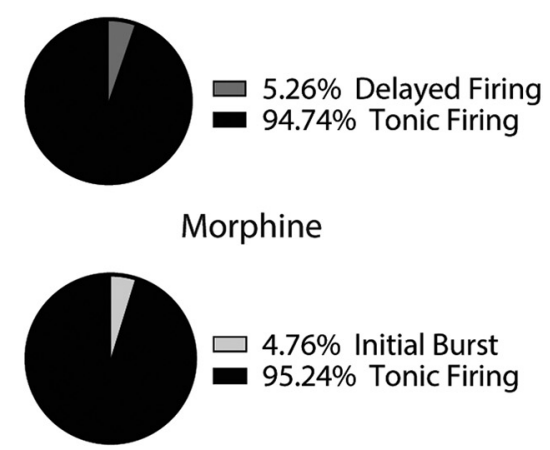

D

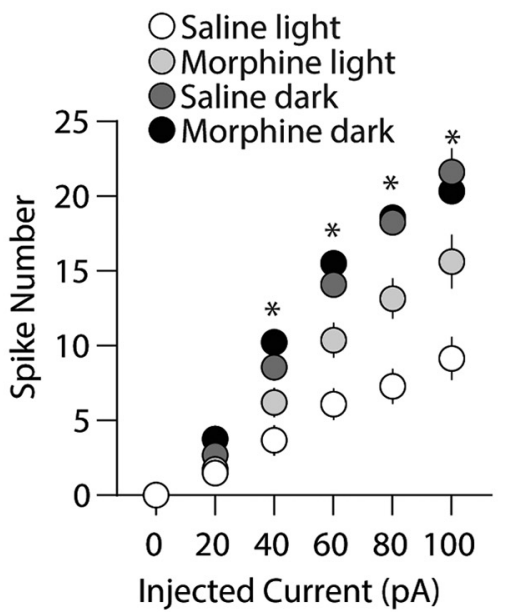

Figure 3. Repeated morphine exposure during the dark cycle has no effect on intrinsic membrane excitability of PVT neurons recorded in the dark cycle. $\boldsymbol{A}$, Example traces demonstrating the two firing phenotypes observed in response to a depolarizing current injection (100 pA for $600 \mathrm{~ms}$ ); tonic and delayed firing (saline, left; morphine, right). PVT neurons from morphine-treated animals only expressed tonic firing responses to current injected. Scale bars: $40 \mathrm{mV}, 200 \mathrm{~ms}$. B, Quantification of firing phenotypes in PVT neurons following repeated saline or morphine treatment. $\boldsymbol{C}$, Summary showing that $24 \mathrm{~h}$ following repeated morphine injections during the dark cycle, the number of action potentials fired in PVT neurons is unaltered $\left(F_{(5,190)}=1.41, p=0.221\right.$; two-way repeated measures ANOVA with Bonferroni post hoc test; saline: $n=19 / 5$; morphine: 21/6). $\boldsymbol{D}$, Summary showing intrinsic membrane excitability of PVT neurons recorded during the light or dark cycle in saline-treated or morphine-treated animals (Bonferroni post hoc test; $40 \mathrm{pA}$ : saline light versus saline dark**, morphine light vs morphine dark**, saline light vs morphine dark*; 60 pA: saline light versus saline dark**, morphine light vs morphine dark**, saline light vs morphine dark**, morphine light vs saline dark*, saline light vs morphine light**; 80 pA: saline light vs saline dark**, morphine light vs morphine dark $* *$, saline light vs morphine dark $* *$, morphine light vs saline dark**, saline light vs morphine light $* * ; 100$ pA: saline light vs saline dark**, morphine light vs morphine dark**, saline light vs morphine dark**, morphine light vs saline dark**, saline light vs morphine light $* * ; * p<0.05, * * p<0.01$; light $=$ light cycle; dark = dark cycle.

during the dark cycle exhibited two firing phenotypes; tonic firing $(94.74 \%)$ or delayed-firing (5.26\%). A $\chi^{2}$ analysis revealed a significant interaction between the timing of saline exposure (i.e., saline-treated during the light vs dark cycle) and firing type $\left(\chi^{2}(3)=14.45, p=0.002\right)$, which is consistent with previous findings (Kolaj et al., 2012). In animals treated with morphine during their dark cycle, PVT neurons ( $n=21$ cells, six animals) exhibited tonic firing (Fig. $3 A, B$ ) and initial burst, but lacked delayed firing, which was observed when morphine was administered during the animals' light cycle (Fig. 2B). Despite the difference in neuronal firing patterns in morphine-light cycle versus morphine-dark cycle groups, a $\chi^{2}$ analysis revealed no significant interaction between the timing of morphine exposure and firing type $\left(\chi^{2}(2)=4.97, p=\right.$ 0.08). Furthermore, an analysis of PVT neuronal intrinsic membrane excitability in dark cycle saline-treated versus morphine-treated animals revealed no significant differences $\left(F_{(5,190)}=1.41, p=0.221\right.$; two-way repeated measures ANOVA; Fig. $3 C$ ) suggesting that PVT neurons are maximally excited during periods of activity, thus occluding morphine-induced alterations in PVT excitability. This interpretation is supported by no significant interactions between morphine exposure and firing type during the dark cycle $\left(\chi^{2}(2)=2.01, p=0.38\right)$.

We next compared PVT neuronal membrane excitability in animals treated with saline during the dark cycle with animals treated with morphine during the light cycle. This comparison was made to investigate whether morphineinduced increases in PVT neuronal membrane excitability mimic the PVT neuronal membrane excitability that occurs during the active, dark cycle of saline-treated ani- 

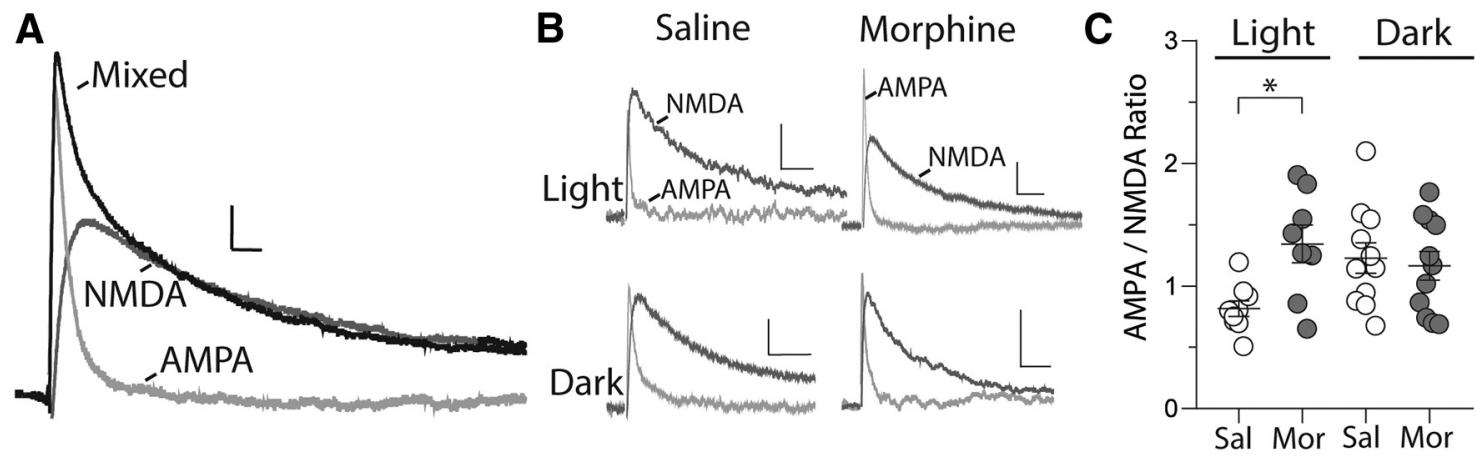

Figure 4. Twenty-four hours following repeated morphine injections during the light cycle, AMPAR/NMDAR ratios are increased on PVT neurons. A, Example traces showing pharmacological separation of AMPAR and NMDAR EPSCs. Scale bars: 12.5 pA, 10 ms. $\boldsymbol{B}$, Example traces illustrating AMPAR-mediated and NMDAR-mediated currents recorded from neurons in the PVT $24 \mathrm{~h}$ following the last saline or morphine injection. Scale bars: $12.5 \mathrm{pA}, 50 \mathrm{~ms}$. $\boldsymbol{C}$, Summary showing a significantly increased AMPAR/NMDAR ratio in PVT neurons following repeated morphine injection during the light cycle but not during the dark cycle $\left(F_{(3,35)}=3.30, p=0.032\right.$, one-way ANOVA with Bonferroni post hoc test; $n=$ cells/mice: light cycle: saline $($ Sal) = 9/5, morphine (Mor) = 8/4; dark cycle: saline = 11/6, morphine $=11 / 6) ; * p<0.05$; light $=$ light cycle; dark $=$ dark cycle.

mals. The results show that dark cycle saline-treated animals express significantly greater evoked action potential firing versus light cycle morphine-treated animals $\left(F_{(15,380)}=9.86, p<0.0001\right.$; two-way repeated measures ANOVA; Fig. 3D). These results suggest that administration of morphine during periods of inactivity (i.e., light cycle) are sufficient to increase PVT neuron intrinsic membrane excitability, but not to levels comparable to those observed during the animals' active state.

\section{Morphine exposure during the light cycle increases AMPAR/NMDAR ratios on PVT neurons}

Given that excitatory ionotropic glutamate receptor activation is a key regulator of PVT neuronal action potential firing (Hermes and Renaud, 2011), we investigated whether excitatory synaptic transmission was altered on PVT neurons following morphine exposure and whether any potential changes were dependent on the timing of morphine administration. To assess potential changes in excitatory postsynaptic strength, we measured AMPAR/NMDAR ratios in saline or morphine-treated animals in both the light and dark cycles. AMPAR/NMDAR ratio is relatively independent of the number of synapses, presynaptic release probability, and other presynaptic factors (Graziane and Dong, 2016). Therefore, a change in this ratio should reflect changes in postsynaptic AMPARs or NMDARs.

Using whole-cell recordings, we observed a significant increase in the AMPAR/NMDAR ratios in morphinetreated animals relative to saline controls when treatments or recordings were performed during the light cycle (one-way ANOVA with Bonferroni post hoc test, $p=$ 0.036; Fig. $4 A-C$ ). In contrast, no significant difference in AMPAR/NMDAR ratios were observed between saline or morphine-treated animals when treatments or recordings took place during the dark cycle (one-way ANOVA with Bonferroni post hoc test, $p>0.999$; Fig. 4C). These results highlight that morphine-induced alterations in glutamatergic transmission on PVT neurons is dependent on the timing of morphine administration.

\section{Morphine-induced place preference is not} modulated by the timing of morphine administration

Given that (1) PVT activity plays a role in drug-seeking behaviors (Hamlin et al., 2009; Browning et al., 2014; Haight et al., 2015) and (2) our results show that morphine differentially influences PVT activity based on the timing of morphine treatment, we investigated whether the timing of morphine injections impacts addiction-like behaviors using the CPP model (Napier et al., 2013). Mice received daily, alternating conditioning for 40 min either with saline or with drug (saline control or morphine), separated by $6 \mathrm{~h}$ for $5 \mathrm{~d}$ (Fig. $5 A, B$ ), which has previously been shown to produce robust morphine-induced CPP (Graziane et al., 2016). Morphine (10 mg/kg, i.p.) pairings (or saline control) were administered at ZT8, ZT13, or ZT21 [saline pairings in the most preferred compartment took place $6 \mathrm{~h}$ prior; 12/12 h light/dark cycle; lights on ZT0 (7 A.M.) to ZT12 (7 P.M.)]. The time points of ZT8 and ZT13 are in accordance with our electrophysiological assessments during the light and dark cycles, respectively (Figs. 1A and 5A). The ZT21 time point was selected because it allowed us to control for potential confounding factors caused by light/dark cycle-induced variations in conditioning, i.e., animals were conditioned with either saline or morphine during the animals' dark cycle (our experimental paradigm required the separation of saline and morphine conditioning sessions by $6 \mathrm{~h}$ with morphine following saline to allow time for morphine to be excreted before the next training day). Our results show that nocturnal mice display typical variations in locomotor activity (Schwartz and Zimmerman, 1990) as saline-treated, control mice showed significant increases in activity counts during pairings that occurred during the dark cycle (ZT13 or ZT21) compared to pairings that occurred during the light cycle (ZT8) on the last day of conditioning (Bonferroni post hoc test, ZT8 vs ZT13: $p<$ 0.0001; ZT8 vs ZT21: $p<0.0001$; Fig. $5 C$ ). Additionally, the timing of morphine injections did influence activity counts as a pairwise comparison revealed a significant increase in activity observed when morphine was administered at ZT8 versus ZT13 on the last day of conditioning 
A

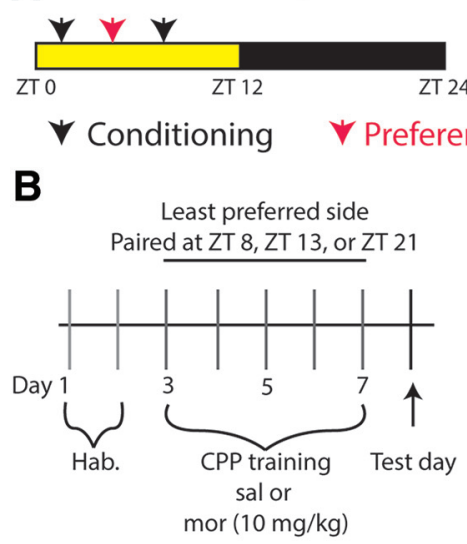

E $\begin{array}{lll}O \text { Sal-8 } & \otimes \text { Mor-13 } & \text { Sal-21 } \\ \text { O Mor-8 } & \otimes \text { Sal-13 } & \text { Mor-21 }\end{array}$

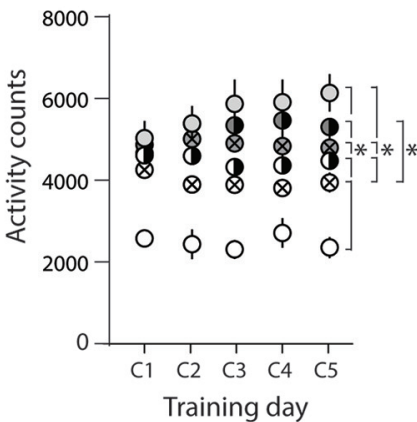

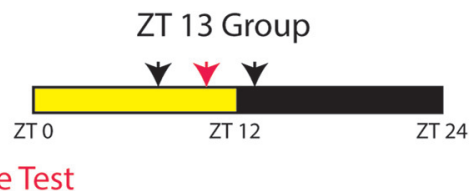

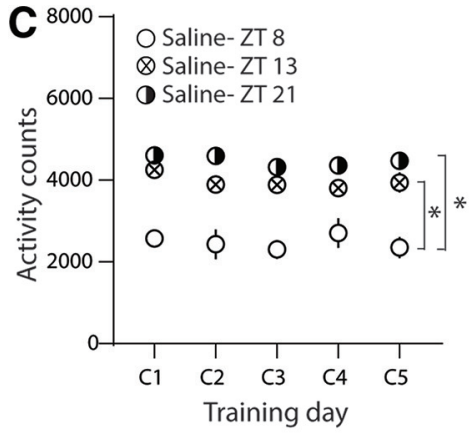

F $\begin{array}{lll}\text { O Sal-8 } & \otimes \text { Mor-13 } & \text { Sal-21 } \\ \text { OMor-8 } & \otimes \text { Sal-13 } & \text { Mor-2 }\end{array}$

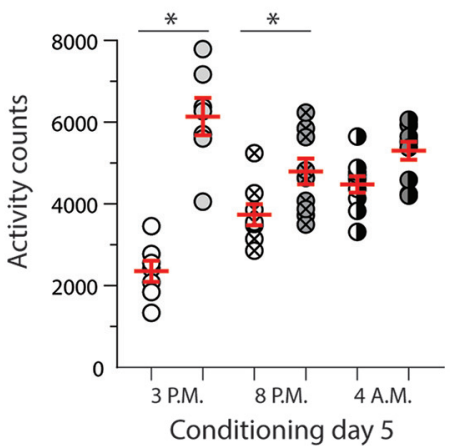

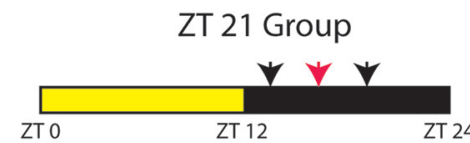

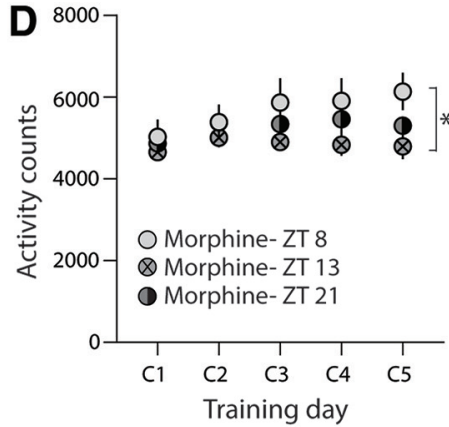

G $\begin{array}{lll}\bigcirc \text { Sal-8 } & \otimes \text { Mor-13 } & \text { Sal-21 } \\ \bigcirc \text { Mor-8 } & \otimes \text { Sal-13 } & \text { Mor-21 }\end{array}$

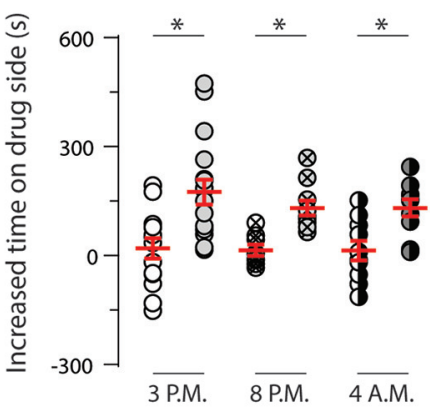

Figure 5. The time of day of morphine conditioning does not influence morphine-induced CPP. A, CPP experimental groups. $\boldsymbol{B}$, Time line of CPP procedure. Mice were allowed to acclimate to the chambers for $2 \mathrm{~d}$ during habituation (Hab). During conditioning (days 3-7), mice were injected with saline (sal) or morphine (mor; $10 \mathrm{mg} / \mathrm{kg}$, i.p.) and paired with the least preferred side at either ZT8, ZT13, or ZT21 CPP tests were performed $24 \mathrm{~h}$ postconditioning. C, Summary showing activity counts for saline-treated animals during conditioning days (C1-C5) at each time point measured (ZT8, ZT13, or ZT21) [saline (Sal)-ZT8: $n=7$; saline (Sal)-ZT13: $n=8$; saline (Sal)-ZT21: $n=10 ; F_{(8,88)}=0.766, p=0.63$; two-way repeated measures ANOVA with Bonferroni post hoc test]; $* p<0.05$. $\boldsymbol{D}$, Summary showing activity counts for morphine-treated animals during conditioning days (C1-C5) at each time point measured (ZT8, ZT13, or ZT21; morphine (Mor)-ZT8: $n=7$; morphine (Mor)-ZT13: $n=10$; morphine (Mor)-ZT21: $n=10 ; F_{(8,96)}=1.48, p=0.17$; two-way repeated measures ANOVA with Bonferroni post hoc test]; $* p<0.05$. E. Summary showing activity counts for saline (Sal)-treated or morphine (Mor)-treated animals during conditioning days (C1-C5) at each time point measured (ZT8, ZT13, or ZT21); [saline (Sal)-ZT8: $n=7$; morphine (Mor)-ZT8: $n=7$; saline (Sal)-ZT13: $n=8$; morphine (Mor)-ZT13: $n=10$; saline (Sal)-ZT21: $n=$ 10; morphine (Mor)-ZT21: $n=10 ; F_{(20,184)}=2.08, p=0.006$, two-way repeated measures ANOVA with Bonferroni post hoc test]; $* p$ $<0.05$. $\boldsymbol{F}$, Summary showing activity counts for saline (Sal)-treated or morphine (Mor)-treated animals mice on conditioning day 5 at each time point measured [saline (Sal)-ZT8: $n=7$; morphine (Mor)-ZT8: $n=7$; saline (Sal)-ZT13: $n=8$; morphine (Mor)-ZT13: $n=$ 10; saline (Sal)-ZT21: $n=10$; morphine (Mor)-ZT21: $n=10 ; F_{(5,46)}=17.6, p<0.0001$, one-way ANOVA with Bonferroni post hoc test]; $* p<0.05$. G, Summary showing that the time of day of morphine conditioning does not influence morphine-induced CPP [saline (Sal)-ZT8: $n=14$; morphine (Mor)-ZT8: $n=17$; saline (Sal)-ZT13: $n=8$; morphine (Mor)-ZT13: $n=10$; saline (Sal)-ZT21: $n=10$; morphine (Mor)-ZT21: $n=10 ; F_{(2,63)}=0.267, p=0.767$; two-way ANOVA with Bonferroni post hoc test]; *p $<0.05$.

(Bonferroni post hoc test, conditioning day 5 (C5): $p=$ 0.02 ; Fig. $5 D$ ). By conditioning day 5 , differences in activity counts were not observed between saline-conditioned or morphine-conditioned animals when pairings occurred at ZT21 (Bonferroni post hoc test, $p=0.47$; Fig. 5E,F), which suggests at this time point that locomotor activity reached maximal levels. Finally, our results show that our morphine training paradigm elicits robust CPP at each conditioning time point assessed (Bonferroni post hoc test, ZT8: $p=0.0002$; ZT13: $p=0.049$; ZT21: $p=0.032$; Fig. $5 G$ ). These results suggest that although repeated morphine injections elicit differential changes in PVT neu- ronal activity, which are dependent on the timing of morphine administration, these temporal effects are not sufficient to prevent morphine-induced CPP.

\section{Discussion}

Our results show that repeated morphine administration during the light cycle is sufficient to increase spontaneous firing of PVT neurons along with increasing PVT neuronal intrinsic membrane excitability and excitatory synaptic glutamatergic transmission at the 24-h abstinent time point. Furthermore, we found that this morphine-induced effect was absent when morphine 
administration or recordings occurred during the animals' active state (i.e., dark cycle). Finally, we found that while the timing of morphine administration differentially alters PVT neuronal excitability, it did not impact morphine-induced drug-seeking behaviors measured using CPP.

\section{Diurnal variations of PVT firing activity and postsynaptic response to excitatory glutamatergic transmission}

The diurnal variations in PVT firing observed (Fig. 1) coincided with a previous report showing that PVT neurons express high levels of spontaneous activity, both as tonic and burst firing, during darkness corresponding to the nocturnal animals' period of activity (Kolaj et al., 2012). These variations in basal firing are correlated with alterations in intrinsic neuronal properties including an elevated membrane resistance and a lower membrane conductance (Kolaj et al., 2012). In agreement with this, we found that PVT neurons recorded from saline-treated mice during the dark cycle expressed depolarized membrane potentials and displayed increases in membrane resistance (membrane resistance: saline-treated light cycle: $562.4 \pm$ $54.2 \mathrm{M} \Omega$; saline-treated dark cycle: $1149 \pm 129 \mathrm{M} \Omega$; $t_{(43)}=$ 4.26, $p=0.0001$, Student's $t$-test; resting membrane potential: saline-treated light cycle: $-59.36 \pm 0.90 \mathrm{mV}$; saline-treated dark cycle: $-51.38 \pm 1.04 \mathrm{mV} ; t_{(64)}=5.810$, $p<0.0001$, Student's $t$-test; Table 2). Furthermore, previous reports have shown that during the day, when animals are at rest, PVT neurons are "silent," as spontaneous activity is significantly reduced (Kolaj et al., 2012). These firing properties are typical of thalamic neurons, which can express either tonic or burst firing (Jahnsen and Llinás, 1984; Crunelli et al., 2005; Steriade, 2005; Wong et al., 2013), corresponding to states of arousal; burst firing is observed during slow-wave sleep and wakefulness, whereas tonic firing is observed during wakefulness or is sufficient to induce wakefulness (McCormick and Bal, 1997; Reinagel et al., 1999; Fanselow et al., 2001; Llinás and Steriade, 2006; Ren et al., 2018). However, a unique feature of the PVT is that the neuronal firing properties are dynamically controlled by the circadian time of day (Colavito et al., 2015). Our results reiterate this circadian dependent PVT activity as, under control conditions, PVT neuronal firing in response to current injections was significantly increased during the night versus during the day (Figs. 2, 3).

One potential factor contributing to PVT diurnal variations is excitatory glutamatergic input, as PVT neurons receive excitatory synaptic input that determines their spontaneous firing discharge (Hermes and Renaud, 2011). We found that under control conditions, excitatory glutamatergic transmission at PVT synaptic connections does express diurnal variations as AMPAR/NMDAR ratios were significantly different when comparisons were made between saline-treated animals during the day versus saline-treated animals during the night (AMPAR/NMDAR ratios, saline-light cycle vs saline-dark cycle $t_{(18)}=2.76$, $p=0.01$, Student's $t$-test). These results demonstrate a circadian-cycle-dependent effect on the postsynaptic re- sponse to glutamate. Additionally, although not analyzed here, presynaptic factors may also be altered by circadian cycles, including probability of glutamate release on PVT neurons, which, according to quantal theory, could impact the frequency of glutamate transmission (Redman, 1990).

We should note that some differences exist, despite some similarities of our results to other studies. We observed only two firing phenotypes from PVT neurons during dark cycle recordings in our saline-treated mice, including delayed firing and tonic firing. Others have identified three extra firing phenotypes including reluctant firing, initial burst, and single spiking (Yeoh et al., 2014). The reasons for this discrepancy are unclear, however, between the studies, a number of differences exist, including bath temperature used during recordings (22$24^{\circ} \mathrm{C}$ vs $33^{\circ} \mathrm{C}$ ) and/or the PVT region recorded (mPVT vs aPVT). Additionally, other studies have shown far less tonic firing neurons during the dark phase compared to what we observed (Kolaj et al., 2012). A potential explanation for this are differences in species (mice vs rats) or treatments (saline-treated vs naive) between the studies (We understand that saline treatment is unlikely to elicit changes in PVT firing, however, repeated experimentermediated injections may alter levels of arousal and could potentially be responsible for the differences observed). All in all, these findings demonstrate that, due to variations that may take place from study to study, it is important to acquire the necessary number of control conditions when performing PVT neuronal recordings.

Lastly, we acknowledge that we randomly sampled PVT neurons. It is known that the PVT consists primarily of glutamatergic neurons (Christie et al., 1987; Frassoni et al., 1997; Csáki et al., 2000; Myers et al., 2014), but other populations have been identified including enkephalin, substance $\mathrm{P}$, neurotensin, and galanin (Skofitsch and Jacobowitz, 1985; Melander et al., 1986; Arluison et al., 1994). Based on this, it would be useful for future studies to investigate cell-type specific activity during stages of vigilance and the corresponding effects produced by drugs of abuse.

\section{PVT activity following morphine administration}

Twenty-four hours following a $5 \mathrm{~d}$, once daily, repeated morphine administration paradigm, we found that PVT neuronal spontaneous firing (Fig. 1), intrinsic membrane excitability (Fig. 2), and response to excitatory glutamatergic transmission (Fig. 4) are all preferentially increased during light cycle morphine administration and electrophysiological recordings. Furthermore, we found that the intrinsic membrane excitability was significantly increased in tonically firing neurons originating from morphinetreated animals, but only at the maximum current injection tested (100 pA; Fig. 2D). This suggests that, following morphine treatment, the signal transmission on PVT neurons may be maintained over a greater range of frequencies and/or allow PVT neurons to sample greater sets of afferent signals made up of higher frequency compositions. Lastly, we did not observe any changes in PVT activity or response to excitatory synaptic inputs during 
dark cycle morphine administration and recordings due to the already elevated levels under control conditions.

Although the mechanisms mediating this diurnal morphine-induced shift to tonic firing are unknown, there is evidence that ion channels and/or specific neurotransmitters may mediate the observed changes. It has been reported previously that under basal conditions, T-type low-voltage-activated $\mathrm{Ca}^{2+}$ currents as well as hyperpolarization-activated cation currents $\left(\mathrm{I}_{\mathrm{H}}\right)$ are increased on PVT neurons during the dark cycle, potentially contributing to the observed increases in firing (Kolaj et al., 2012). Our results suggest that differences existed in PVT neuron $I_{H}$ currents between saline-treated animals sampled from the light versus dark cycles measured by the voltage sag induced by hyperpolarizing current injections $\left(t_{(29)}=2.05\right.$, $p=0.0499$, Student's $t$-test; Table 2). However, we did not observe any changes in putative $\mathrm{I}_{\mathrm{H}}$ currents when comparisons were made between saline and morphine groups during the light $\left(t_{(28)}=0.663, p=0.5128\right.$, Student's $t$-test) or dark phases $\left(t_{(33)}=0.204, p=0.8397\right.$, Student's t-test; see Table 2), which suggests that the morphine-induced shift may not be mediated by $\mathrm{I}_{\mathrm{H}}$ currents.

Another potential mechanism mediating the morphineinduced shift to tonic firing are $\mathrm{N}$-type $\mathrm{Ca}^{2+}$ channels and small-conductance $\mathrm{Ca}^{2+}$-dependent $\mathrm{K}^{+}$(SK) channels, which are involved in maintaining tonic firing patterns following current injections (Wong et al., 2013). In morphinetreated animals, we observed that the frequency of tonically firing PVT neurons was not affected by the time of day that morphine was administered (two-way ANOVA with Bonferroni post hoc test, $p>0.99$; Fig. $3 D$ ). Therefore, it is plausible that morphine administration during the light cycle may influence PVT neuronal firing in much the same way as the circadian cycle, which increases T-type and/or N-type $\mathrm{Ca}^{2+}$ currents along with SK-mediated currents to elicit increases in the expression of tonically firing PVT neurons.

In addition to ion channels, morphine may impact PVT neuronal firing through its modulation of neurotransmitter release. Both vasopressin and orexin, neurotransmitters whose expression are likely modulated by morphine (Aziz et al., 1981; Harris et al., 2005), elicit a switch between bursting to tonically firing phenotypes in PVT neurons (Zhang et al., 2006; Kolaj et al., 2007).

Future studies investigating the mechanisms mediating morphine's effects on PVT neurons during inactive states will enable direct PVT neuronal manipulations to attenuate or augment morphine-induced changes. These direct manipulations have the potential to reveal whether the PVT responses to morphine during short-term abstinence are sufficient to block drug-seeking behaviors induced by stress, cues/context, or drug-priming injections. Here, we used the temporal effects observed to investigate whether context-induced morphine-seeking behaviors could be prevented by timing injections of morphine with suboptimal changes in PVT activity (ZT13) as observed from our electrophysiological experiments (Figs. 1, 4). We found that morphine-induced increases in locomotor activity were influenced by time of day, which was due to an increase in basal locomotor activity, as saline-treated an- imals demonstrated comparable activity counts versus morphine-treated animals. Additionally, we found that morphine conditioning at ZT8 facilitated greater activity by the fifth conditioning day compared to morphine administration at ZT13. We did not directly investigate the mechanisms and/or brain regions mediating the observed temporal effect on morphine-induced locomotor activity. However, dopamine may play a role, as it has been shown previously that dopamine expression is dependent on the circadian cycle (Schade et al., 1995; Hood et al., 2010), and that dopamine can directly influence locomotor activity (Pijnenburg et al., 1976; Isaacson et al., 1978; Fifel and Cooper, 2014).

Although timing morphine conditioning with periods of vigilance did not alter morphine-induced drug seeking as measured using the CPP paradigm (Fig. 5F), our electrophysiological findings, and previously published studies from others, suggest that morphine-induced PVT alterations may impact reward-seeking behaviors (Matzeu et al., 2014, 2016; Matzeu and Martin-Fardon, 2018). For example, previous studies have shown that increases in PVT glutamatergic transmission in the nucleus accumbens induces aversion and blocks seeking for natural rewards (Zhu et al., 2016; Do-Monte et al., 2017), while decreasing PVT glutamatergic transmission in the accumbens increases seeking to natural rewards and increases food consumption (Do-Monte et al., 2017; Reed et al., 2018). Furthermore, the acquisition of natural-or drugseeking behaviors is increased (in respect to sucrose) or decreased (in respect to cocaine) with increases or decreases in PVT to nucleus accumbens transmission, respectively (Labouèbe et al., 2016; Neumann et al., 2016). In addition, it has been shown that cues predicting reward elicit decreases in PVT activity likely mediated by decreases in prefrontal cortical glutamate transmission (Otis et al., 2019). Lastly, reducing glutamatergic transmission in the PVT attenuates drug-induced reinstatement to cocaine (James et al., 2010; Yeoh et al., 2014) and inhibition of the PVT, via intraposterior PVT administration of the $\mathrm{GABA}_{\mathrm{A}}$ and $\mathrm{GABA}_{\mathrm{B}}$ receptor agonists muscimol and baclofen, blocked cue-induced reinstatement to cocaine (Matzeu et al., 2015). All in all, it is clear that PVT activity plays a role in reward seeking and responds to cuereward associations suggesting that other models of substance use disorder, including self-administration, may be worthwhile models to test the timing of morphine administration on drug-seeking behaviors.

Lastly, our studies have focused on a morphine dose (10 $\mathrm{mg} / \mathrm{kg}$, i.p.) that does not produce noticeable signs of opioid withdrawal (Robinson and Kolb, 1999), but rather elicits locomotor sensitization and CPP (Spanagel et al., 1998; Mueller et al., 2002; Graziane et al., 2016). We have not tested whether escalating doses of morphine, that are known to produce somatic signs of withdrawal, would elicit similar effects on PVT neuronal activity in either the light or dark cycles. Evidence suggests that independent neurocircuits may be implicated in the somatic and affective responses to acute opioid withdrawal (Aston-Jones et al., 1999; Delfs et al., 2000). Therefore, understanding how PVT neurons are affected by varying the morphine 
dose may have implications in different states of opioid abstinence, including a state of early abstinence in opioiddependent patients known to experience withdrawal symptoms or a state of prolonged abstinence in patients having already undergone opioid withdrawal.

\section{Sleep disturbances and relapse}

Our results indicate that during morphine abstinence, PVT neuronal firing and excitability is preferentially increased during the animals' inactive state (Figs. 1-Figs. 3), suggesting that the basal rhythms of PVT activity are disrupted following repeated morphine exposure. The PVT is directly involved in mediating wakefulness via increases in tonic firing (7-10 Hz; Ren et al., 2018). Therefore, it is plausible, given that the PVT regulates lightinduced phase shifts in the circadian cycle (SalazarJuárez et al., 2002), that during short-term morphine abstinence, increases in PVT activity during inactive states may induce sleep disturbances via facilitating wakefulness despite external stimuli signaling a period of dormancy. Future studies are required to directly test whether the PVT plays a role in the already observed morphine-induced circadian rhythm shifts, which induce a phase delay or phase advance in circadian oscillations depending on the time of opioid administration (Marchant and Mistlberger, 1995). Doing so may reveal a key brain region mediating morphine-induced changes in circadian rhythms.

Lastly, there is growing evidence that sleep difficulties are a potential risk factor for opioid use disorder and relapse (Oyefeso et al., 1997; Hasler et al., 2012; Logan et al., 2014, 2018). In rats, morphine delays the onset of REM sleep and in humans, morphine decreases the number and duration of REM periods, delays REM onset, increases the waking state during the early night, and increases NREM light sleep (stages 1 and 2), while decreasing NREM deep sleep (stages 3 and 4; Kay et al., 1969; Arankowsky-Sandoval and Gold, 1995). These disruptions in sleep patterns are correlated with drugseeking behaviors as an interaction between time of day, and drug-seeking behaviors have been shown in rats, who will self-administer more heroin and exhibit more drug-seeking behaviors when training takes place during the dark phase versus the light phase (Coffey et al., 2018). Additionally, light/dark cycle alterations have been shown to alter morphine-induced CPP (Tahsili-Fahadan et al., 2005). Taken together, these results suggest that drugseeking behaviors may be avoidable in some patients if corrections can be made to drug-induced sleep disturbances. Despite our results showing that context-induced morphine-seeking behaviors were not dependent on time of morphine injection, it does not rule out that a chronotherapy approach with morphine may alleviate drugseeking behaviors, which may be investigated in future studies using other models of substance use disorder including self-administration. The idea that chronotherapy may mitigate rewarding properties of drugs is in line with evidence suggesting that chronopharmacology impacts other morphine-induced effects, including analgesia (Yoshida et al., 2003; Yu et al., 2015).

\section{References}

Abarca C, Albrecht U, Spanagel R (2002) Cocaine sensitization and reward are under the influence of circadian genes and rhythm. Proc Natl Acad Sci USA 99:9026-9030.

Arankowsky-Sandoval G, Gold PE (1995) Morphine-induced deficits in sleep patterns: attenuation by glucose. Neurobiol Learn Mem 64:133-138.

Arluison M, Brochier G, Vankova M, Leviel V, Villalobos J, Tramu G (1994) Demonstration of peptidergic afferents to the bed nucleus of the stria terminalis using local injections of colchicine. A combined immunohistochemical and retrograde tracing study. Brain Res Bull 34:319-337.

Aston-Jones G, Delfs JM, Druhan J, Zhu Y (1999) The bed nucleus of the stria terminalis. A target site for noradrenergic actions in opiate withdrawal. Ann NY Acad Sci 877:486-498.

Aziz LA, Forsling ML, Woolf CJ (1981) The effect of intracerebroventricular injections of morphine on vasopressin release in the rat. $J$ Physiol 311:401-409.

Bardo MT, Bevins RA (2000) Conditioned place preference: what does it add to our preclinical understanding of drug reward? Psychopharmacology 153:31-43.

Bohn LM, Gainetdinov RR, Sotnikova TD, Medvedev IO, Lefkowitz RJ, Dykstra LA, Caron MG (2003) Enhanced rewarding properties of morphine, but not cocaine, in beta(arrestin)-2 knock-out mice. $J$ Neurosci 23:10265-10273.

Browning JR, Jansen HT, Sorg BA (2014) Inactivation of the paraventricular thalamus abolishes the expression of cocaine conditioned place preference in rats. Drug Alcohol Depend 134:387390.

Christie MJ, Summers RJ, Stephenson JA, Cook CJ, Beart PM (1987) Excitatory amino acid projections to the nucleus accumbens septi in the rat: a retrograde transport study utilizingd[3H]aspartate and [3H]GABA. Neuroscience 22:425-439.

Coffey AA, Fang J, Grigson PS (2018) Heroin self-administration as a function of time of day in rats. Psychopharmacology 235:30053015.

Colavito V, Tesoriero C, Wirtu AT, Grassi-Zucconi G, Bentivoglio M (2015) Limbic thalamus and state-dependent behavior: the paraventricular nucleus of the thalamic midline as a node in circadian timing and sleep/wake-regulatory networks. Neurosci Biobehav Rev 54:3-17.

Crunelli V, Tóth TI, Cope DW, Blethyn K, Hughes SW (2005) The 'window' T-type calcium current in brain dynamics of different behavioural states. J Physiol 562:121-129.

Csáki Á, Kocsis K, Halász B, Kiss J (2000) Localization of glutamatergic/aspartatergic neurons projecting to the hypothalamic paraventricular nucleus studied by retrograde transport of $[3 \mathrm{H}] \mathrm{d}-$ aspartate autoradiography. Neuroscience 101:637-655.

Daoudal G, Debanne D (2003) Long-term plasticity of intrinsic excitability: learning rules and mechanisms. Learn Mem 10:456-465.

Delfs JM, Zhu Y, Druhan JP, Aston-Jones G (2000) Noradrenaline in the ventral forebrain is critical for opiate withdrawal-induced aversion. Nature 403:430-434.

Desai NS, Rutherford LC, Turrigiano GG (1999) Plasticity in the intrinsic excitability of cortical pyramidal neurons. Nat Neurosci 2:515-520.

Dimsdale JE, Norman D, DeJardin D, Wallace MS (2007) The effect of opioids on sleep architecture. J Clin Sleep Med 3:33-36.

Do-Monte FH, Minier-Toribio A, Quiñones-Laracuente K, MedinaColón EM, Quirk GJ (2017) Thalamic regulation of sucrose seeking during unexpected reward omission. Neuron 94:388-400.e4.

Dong X, Li S, Kirouac GJ (2017) Collateralization of projections from the paraventricular nucleus of the thalamus to the nucleus accumbens, bed nucleus of the stria terminalis, and central nucleus of the amygdala. Brain Struct Funct 222:3927-3943.

Fanselow EE, Sameshima K, Baccala LA, Nicolelis MA (2001) Thalamic bursting in rats during different awake behavioral states. Proc Natl Acad Sci USA 98:15330-15335. 
Fifel K, Cooper HM (2014) Loss of dopamine disrupts circadian rhythms in a mouse model of Parkinson's disease. Neurobiol Disease 71:359-369.

Frassoni C, Spreafico R, Bentivoglio M (1997) Glutamate, aspartate and co-localization with calbindin in the medial thalamus. An immunohistochemical study in the rat. Exp Brain Res 115:95-104.

Graziane N, Dong Y (2016) Electrophysiological analysis of synaptic transmission. New York: Springer.

Graziane NM, Sun S, Wright WJ, Jang D, Liu Z, Huang YH, Nestler EJ, Wang YT, Schlüter OM, Dong Y (2016) Opposing mechanisms mediate morphine- and cocaine-induced generation of silent synapses. Nat Neurosci 19:915-925.

Gremel CM, Gabriel KI, Cunningham CL (2006) Topiramate does not affect the acquisition or expression of ethanol conditioned place preference in DBA/2J or C57BL/6J mice. Alcohol Clin Exp Res 30:783-790.

Haight JL, Fraser KM, Akil H, Flagel SB (2015) Lesions of the paraventricular nucleus of the thalamus differentially affect signand goal-tracking conditioned responses. Eur J Neurosci 42: 2478-2488

Hamlin AS, Clemens KJ, Choi EA, McNally GP (2009) Paraventricular thalamus mediates context-induced reinstatement (renewal) of extinguished reward seeking. Eur J Neurosci 29:802-812.

Harris GC, Wimmer M, Aston-Jones G (2005) A role for lateral hypothalamic orexin neurons in reward seeking. Nature 437:556559.

Hasler BP, Smith LJ, Cousins JC, Bootzin RR (2012) Circadian rhythms, sleep, and substance abuse. Sleep Med Rev 16:67-81.

Hermes ML, Renaud LP (2011) Postsynaptic and presynaptic group II metabotropic glutamate receptor activation reduces neuronal excitability in rat midline paraventricular thalamic nucleus. J Pharmacol Exp Ther 336:840-849.

Herrera CG, Cadavieco MC, Jego S, Ponomarenko A, Korotkova T, Adamantidis A (2016) Hypothalamic feedforward inhibition of thalamocortical network controls arousal and consciousness. Nat Neurosci 19:290-298.

Hood S, Cassidy P, Cossette M-P, Weigl Y, Verwey M, Robinson B, Stewart J, Amir S (2010) Endogenous dopamine regulates the rhythm of expression of the clock protein PER2 in the rat dorsal striatum via daily activation of $D_{2}$ dopamine receptors. J Neurosci 30:14046-14058.

Huang YH, Schlüter OM, Dong Y (2011) Cocaine-induced homeostatic regulation and dysregulation of nucleus accumbens neurons. Behav Brain Res 216:9-18.

Isaacson RL, Yongue B, McClearn D (1978) Dopamine agonists: their effect on locomotion and exploration. Behav Biol 23:163-179.

Ishikawa M, Mu P, Moyer JT, Wolf JA, Quock RM, Davies NM, Hu XT, Schluter OM, Dong Y (2009) Homeostatic synapse-driven membrane plasticity in nucleus accumbens neurons. J Neurosci 29: 5820-5831.

Jahnsen H, Llinás R (1984) Ionic basis for the electro-responsiveness and oscillatory properties of guinea-pig thalamic neurones in vitro. J Physiol 349:227-247.

James MH, Charnley JL, Jones E, Levi EM, Yeoh JW, Flynn JR, Smith DW, Dayas CV (2010) Cocaine- and amphetamine-regulated transcript (CART) signaling within the paraventricular thalamus modulates cocaine-seeking behaviour. PLoS One 5:e12980.

Kay DC (1975) Human sleep during chronic morphine intoxication. Psychopharmacologia 44:117-124.

Kay DC, Eisenstein RB, Jasinski DR (1969) Morphine effects on human REM state, waking state and NREM sleep. Psychopharmacologia 14:404-416.

Kirouac GJ (2015) Placing the paraventricular nucleus of the thalamus within the brain circuits that control behavior. Neurosci Biobehav Rev 56:315-329.

Kolaj M, Doroshenko P, Yan Cao X, Coderre E, Renaud LP (2007) Orexin-induced modulation of state-dependent intrinsic properties in thalamic paraventricular nucleus neurons attenuates action potential patterning and frequency. Neuroscience 147:1066-1075.
Kolaj M, Zhang L, Rønnekleiv OK, Renaud LP (2012) Midline thalamic paraventricular nucleus neurons display diurnal variation in resting membrane potentials, conductances, and firing patterns in vitro. $\mathrm{J}$ Neurophysiol 107:1835-1844.

Koo JW, Lobo MK, Chaudhury D, Labonté B, Friedman A, Heller E, Peña CJ, Han MH, Nestler EJ (2014) Loss of BDNF signaling in D1R-expressing NAc neurons enhances morphine reward by reducing GABA inhibition. Neuropsychopharmacology 39:26462653.

Kurtuncu M, Arslan AD, Akhisaroglu M, Manev H, Uz T (2004) Involvement of the pineal gland in diurnal cocaine reward in mice. Eur J Pharmacol 489:203-205.

Labouèbe G, Boutrel B, Tarussio D, Thorens B (2016) Glucoseresponsive neurons of the paraventricular thalamus control sucrose-seeking behavior. Nat Neurosci 19:999-1002.

Li S, Kirouac GJ (2008) Projections from the paraventricular nucleus of the thalamus to the forebrain, with special emphasis on the extended amygdala. J Comp Neurol 506:263-287.

Li S, Kirouac GJ (2012) Sources of inputs to the anterior and posterior aspects of the paraventricular nucleus of the thalamus. Brain Struct Funct 217:257-273.

Li SX, Shi J, Epstein DH, Wang X, Zhang XL, Bao YP, Zhang D, Zhang XY, Kosten TR, Lu L (2009) Circadian alteration in neurobiology during 30 days of abstinence in heroin users. Biol Psychiatry 65:905-912.

Li Z, Chen Z, Fan G, Li A, Yuan J, Xu T (2018) Cell-type-specific afferent innervation of the nucleus accumbens core and shell. Front Neuroanat 12:84.

Liu Z, Wang Y, Cai L, Li Y, Chen B, Dong Y, Huang YH (2016) Prefrontal cortex to accumbens projections in sleep regulation of reward. J Neurosci 36:7897-7910.

Llinás RR, Steriade M (2006) Bursting of thalamic neurons and states of vigilance. J Neurophysiol 95:3297-3308.

Logan RW, Hasler BP, Forbes EE, Franzen PL, Torregrossa MM, Huang YH, Buysse DJ, Clark DB, McClung CA (2018) Impact of sleep and circadian rhythms on addiction vulnerability in adolescents. Biol Psychiatry 83:987-996.

Logan RW, Williams WP 3rd, McClung CA (2014) Circadian rhythms and addiction: mechanistic insights and future directions. Behav Neurosci 128:387-412.

Marchant EG, Mistlberger RE (1995) Morphine phase-shifts circadian rhythms in mice: role of behavioural activation. Neuroreport 7:209-212.

Mátyás F, Komlósi G, Babiczky Á, Kocsis K, Barthó P, Barsy B, Dávid C, Kanti V, Porrero C, Magyar A, Szúcs I, Clasca F, Acsády L (2018) A highly collateralized thalamic cell type with arousalpredicting activity serves as a key hub for graded state transitions in the forebrain. Nat Neurosci 21:1551-1562.

Matzeu A, Martin-Fardon R (2018) Drug seeking and relapse: new evidence of a role for orexin and dynorphin co-transmission in the paraventricular nucleus of the thalamus. Front Neurol 9:720.

Matzeu A, Zamora-Martinez E, Martin-Fardon R (2014) The paraventricular nucleus of the thalamus is recruited by both natural rewards and drugs of abuse: recent evidence of a pivotal role for orexin/hypocretin signaling in this thalamic nucleus in drugseeking behavior. Front Behav Neurosci 8:117.

Matzeu A, Weiss F, Martin-Fardon R (2015) Transient inactivation of the posterior paraventricular nucleus of the thalamus blocks cocaine-seeking behavior. Neurosci Lett 608:34-39.

Matzeu A, Kerr TM, Weiss F, Martin-Fardon R (2016) Orexin-A hypocretin-1 mediates cocaine-seeking behavior in the posterior paraventricular nucleus of the thalamus via orexin/hypocretin receptor-2. J Pharmacol Exp Ther 359:273-279.

McCormick DA, Bal T (1997) Sleep and arousal: thalamocortical mechanisms. Annu Rev Neurosci 20:185-215.

Melander T, Hökfelt T, Rökaeus A (1986) Distribution of galaninlike immunoreactivity in the rat central nervous system. J Comp Neurol 248:475-517. 
Mueller D, Perdikaris D, Stewart J (2002) Persistence and druginduced reinstatement of a morphine-induced conditioned place preference. Behav Brain Res 136:389-397.

Myers B, Mark Dolgas C, Kasckow J, Cullinan WE, Herman JP (2014) Central stress-integrative circuits: forebrain glutamatergic and GABAergic projections to the dorsomedial hypothalamus, medial preoptic area, and bed nucleus of the stria terminalis. Brain Struct Funct 219:1287-1303.

Napier TC, Herrold AA, de Wit H (2013) Using conditioned place preference to identify relapse prevention medications. Neurosci Biobehav Rev 37:2081-2086.

Nelson AB, Krispel CM, Sekirnjak C, Du Lac S (2003) Long-lasting increases in intrinsic excitability triggered by inhibition. Neuron 40:609-620.

Neumann PA, Wang Y, Yan Y, Wang Y, Ishikawa M, Cui R, Huang YH, Sesack SR, Schlüter OM, Dong Y (2016) Cocaine-induced synaptic alterations in thalamus to nucleus accumbens projection. Neuropsychopharmacology 41:2399-2410.

Novak CM, Nunez AA (1998) Daily rhythms in Fos activity in the rat ventrolateral preoptic area and midline thalamic nuclei. Am J Physiol 275:R1620-R1626.

Novak CM, Harris JA, Smale L, Nunez AA (2000) Suprachiasmatic nucleus projections to the paraventricular thalamic nucleus in nocturnal rats (Rattus norvegicus) and diurnal nile grass rats (Arviacanthis niloticus). Brain Res 874:147-157.

Otis JM, Zhu M, Namboodiri VMK, Cook CA, Kosyk O, Matan AM, Ying R, Hashikawa Y, Hashikawa K, Trujillo-Pisanty I, Guo J, Ung RL, Rodriguez-Romaguera J, Anton ES, Stuber GD (2019) Paraventricular thalamus projection neurons integrate cortical and hypothalamic signals for cue-reward processing. Neuron 103:423431.e4.

Oyefeso A, Sedgwick P, Ghodse H (1997) Subjective sleep-wake parameters in treatment-seeking opiate addicts. Drug Alcohol Depend 48:9-16.

Paxinos G, Franklin KBJ (2004) The mouse brain in stereotaxic coordinates. San Diego: Elsevier Academic Press.

Peng ZC, Bentivoglio M (2004) The thalamic paraventricular nucleus relays information from the suprachiasmatic nucleus to the amygdala: a combined anterograde and retrograde tracing study in the rat at the light and electron microscopic levels. J Neurocytol 33:101-116.

Peng ZC, Grassi-Zucconi G, Bentivoglio M (1995) Fos-related protein expression in the midline paraventricular nucleus of the rat thalamus: basal oscillation and relationship with limbic efferents. Exp Brain Res 104:21-29.

Pijnenburg AJ, Honig WM, Van der Heyden JA, Van Rossum JM (1976) Effects of chemical stimulation of the mesolimbic dopamine system upon locomotor activity. Eur J Pharmacol 35:45-58.

Redman S (1990) Quantal analysis of synaptic potentials in neurons of the central nervous system. Physiol Rev 70:165-198.

Reed SJ, Lafferty CK, Mendoza JA, Yang AK, Davidson TJ, Grosenick L, Deisseroth K, Britt JP (2018) Coordinated reductions in excitatory input to the nucleus accumbens underlie food consumption. Neuron 99:1260-1273.e4.

Reinagel P, Godwin D, Sherman SM, Koch C (1999) Encoding of visual information by LGN bursts. J Neurophysiol 81:2558-2569.

Ren S, Wang Y, Yue F, Cheng X, Dang R, Qiao Q, Sun X, Li X, Jiang Q, Yao J, Qin H, Wang G, Liao X, Gao D, Xia J, Zhang J, Hu B, Yan J, Wang Y, Xu M, et al. (2018) The paraventricular thalamus is a critical thalamic area for wakefulness. Science 362:429-434.

Robertson JA, Purple RJ, Cole P, Zaiwalla Z, Wulff K, Pattinson KT (2016) Sleep disturbance in patients taking opioid medication for chronic back pain. Anaesthesia 71:1296-1307.

Robinson TE, Kolb B (1999) Morphine alters the structure of neurons in the nucleus accumbens and neocortex of rats. Synapse 33:160162.

Salazar-Juárez A, Escobar C, Aguilar-Roblero R (2002) Anterior paraventricular thalamus modulates light-induced phase shifts in cir- cadian rhythmicity in rats. Am J Physiol Regul Integr Comp Physiol 283:R897-R904.

Scammell TE, Arrigoni E, Lipton JO (2017) Neural circuitry of wakefulness and sleep. Neuron 93:747-765.

Schade R, Vick K, Ott T, Sohr R, Pfister C, Bellach J, Golor G, Lemmer B (1995) Circadian rhythms of dopamine and cholecystokinin in nucleus accumbens and striatum of rats-influence on dopaminergic stimulation. Chronobiol Int 12:87-99.

Schierenbeck T, Riemann D, Berger M, Hornyak M (2008) Effect of illicit recreational drugs upon sleep: cocaine, ecstasy and marijuana. Sleep Med Rev 12:381-389.

Schwartz WJ, Zimmerman P (1990) Circadian timekeeping in BALB/c and C57BL/6 inbred mouse strains. J Neurosci 10:3685-3694.

Shaw IR, Lavigne G, Mayer P, Choinière M (2005) Acute intravenous administration of morphine perturbs sleep architecture in healthy pain-free young adults: a preliminary study. Sleep 28:677-682.

Skofitsch G, Jacobowitz DM (1985) Immunohistochemical mapping of galanin-like neurons in the rat central nervous system. Peptides 6:509-546.

Spanagel R, Sillaber I, Zieglgänsberger W, Corrigall WA, Stewart J, Shaham Y (1998) Acamprosate suppresses the expression of morphine-induced sensitization in rats but does not affect heroin self-administration or relapse induced by heroin or stress. Psychopharmacology 139:391-401.

Steriade M (2005) Sleep, epilepsy and thalamic reticular inhibitory neurons. Trends Neurosci 28:317-324.

Stinus L, Robert C, Karasinski P, Limoge A (1998) Continuous quantitative monitoring of spontaneous opiate withdrawal: locomotor activity and sleep disorders. Pharmacol Biochem Behav 59:83-89.

Tahsili-Fahadan P, Yahyavi-Firouz-Abadi N, Ghahremani MH, Dehpour AR (2005) Effect of light/dark cycle alteration on morphineinduced conditioned place preference. Neuroreport 16:20512056.

Tzschentke TM (2007) Measuring reward with the conditioned place preference (CPP) paradigm: update of the last decade. Addict Biol 12:227-462.

Wang J, Ishikawa M, Yang Y, Otaka M, Kim JY, Gardner GR, Stefanik MT, Milovanovic M, Huang YH, Hell JW, Wolf ME, Schlüter OM, Dong $Y$ (2018) Cascades of homeostatic dysregulation promote incubation of cocaine craving. J Neurosci 38:4316-4328.

Wong AY, Borduas JF, Clarke S, Lee KF, Béique JC, Bergeron R (2013) Calcium influx through N-type channels and activation of SK and TRP-like channels regulates tonic firing of neurons in rat paraventricular thalamus. J Neurophysiol 110:2450-2464.

Yeoh JW, James MH, Graham BA, Dayas CV (2014) Electrophysiological characteristics of paraventricular thalamic (PVT) neurons in response to cocaine and cocaine- and amphetamine-regulated transcript (CART). Front Behav Neurosci 8:280.

Yoshida M, Ohdo S, Takane H, Tomiyoshi Y, Matsuo A, Yukawa E, Higuchi S (2003) Chronopharmacology of analgesic effect and its tolerance induced by morphine in mice. J Pharmacol Exp Ther 305:1200-1205.

Yu ZQ, Zhang CL, Xu YJ, Chang MJ, Jin JJ, Luo L, Li XP, Liu D (2015) Chronopharmacology of analgesic effect and tolerance induced by six narcotic analgesics in mice. Drug Res 65:141-146.

Zhang L, Doroshenko P, Cao XY, Irfan N, Coderre E, Kolaj M, Renaud LP (2006) Vasopressin induces depolarization and statedependent firing patterns in rat thalamic paraventricular nucleus neurons in vitro. Am J Physiol Regul Integr Comp Physiol 290: R1226-R1232.

Zhang W, Linden DJ (2003) The other side of the engram: experience-driven changes in neuronal intrinsic excitability. Nat Rev Neurosci 4:885-900.

Zhu Y, Wienecke CF, Nachtrab G, Chen X (2016) A thalamic input to the nucleus accumbens mediates opiate dependence. Nature 530: 219-222. 